\title{
Intermidialidade e (re)construção histórica no romance gráfico Independência ou mortos
}

\author{
Stanis David Lacowicz
}

\begin{abstract}
Obras artísticas, literárias ou não, que se voltam à história sempre tiveram um grande apelo perante o público. Tal sedução do elemento histórico já era percebida na receptividade do romance histórico aos moldes de Walter Scott, com seus Waverley (1814) e Ivanhoé (1819). Este último se disseminou pela Europa tanto entre leitores quanto autores, que acabavam, em seus próprios projetos literários, guiando-se por formas semelhantes de reconstruir na literatura um determinado período da história de seus países, num claro intento de pensar, construir e divulgar uma identidade nacional específica. As produções narrativas no século XX, sobretudo no caso do cinema, retomaram muito dessa tradição literária de buscar no documento histórico os elementos, temas, acontecimentos e personagens para construírem seus enredos, agora com o aspecto deslumbrante que a imagem fílmica provocaria nos espectadores, promovendo uma nova forma de se envolverem com a obra ficcional.
\end{abstract}

De certo modo, a ficção histórica permite uma viagem no tempo, manejando o desdobrar de nossos desejos na sua articulação com a memória, a experiência de sair de si próprio e, nesse caso, encontrar-se com um outro tempo e espaço, mesmo com todas as ilusões que podem ser criadas sobre a época retratada. Como na imagem evocada pelo estudioso do romance histórico brasileiro Antonio Roberto Esteves, essas obras se mostram como uma possibilidade segura de encarar o desconhecido, como se fosse uma "viagem ao sótão dos avós, onde se podem reviver pessoas, diálogos e episódios, mesmo aqueles mais dramáticos, com a segurança de que, fechada a porta, ou seja, fechado o livro, tudo voltará ao normal" (Esteves, 2010, p. 65).

Nesse misto de curiosidade, de luta contra o esquecimento e de necessidade de (co)memoração, a busca dos leitores e espectadores pela ficção histórica demonstra tanto o potencial mercadológico dessa modalidade narrativa quanto a sua capacidade de congregar uma memória coletiva, um espaço para reforçar um determinado imaginário estabelecido ou hegemônico. Por outro lado, a ficção histórica, sobretudo em obras de corte pós-moderno, mostra-se como o palco privilegiado para promover o efeito disjuntivo na releitura dos signos da história, pondo

Doutorando do curso de pós-graduação em Letras da Universidade Federal do Paraná. E-mail: stanislac@gmail.com. 
sob crítica memórias institucionais, bem como esquecimentos arquitetados e impostos, problematizando a possibilidade de um conhecimento do passado que não seja mediado pela linguagem. Não se trata, pois, de negar a existência do tempo, do passado ou dos acontecimentos, mas de percebê-los em sua existência textual, discursiva, e de que só temos acesso a eles por meio de seus "vestígios textualizados" (Hutcheon, 1991, p. 157). Dessa maneira, evidencia-se nossa filiação à forma como Linda Hutcheon pensa as aproximações entre literatura e história, alinhada às perspectivas do historiador Hayden White, vendo ambas como discursos, sobre os quais há um processo de seleção, edição e principalmente omissões, processo situado ideologicamente, segundo interesses ou valores daqueles que compõem e para quem compõem (HuTCHEON, 1991).

Levando em conta essas questões sobre a ficção histórica em sua vertente contemporânea, pretendemos neste trabalho analisar a reconstrução ficcional da personagem histórica de D. Pedro I no romance gráfico Independência ou Mortos (2012), de Abu Fobiya (roteirista, pseudônimo de Fabio Abu) e Harald Stricker (ilustrador e corroteirista). Nesse processo, buscaremos evidenciar a forma como algumas das relações intertextuais e intermidiáticas que se operam na obra são fundamentais para a produção de sentidos em torno da reencenação da história. Numa mescla de linguagem verbal e visual, essa obra narra desde a vinda da família real portuguesa ao Brasil (1808) até a proclamação e luta pela Independência (1822). Entretanto, num intento de construir um passado alternativo, eventos históricos conhecidos são intercalados com um elemento sobrenatural: os zumbis devoradores de carne humana, monstros que na obra são denominados "bestas". Com isso, a luta pela independência do Brasil frente aos portugueses se torna também a luta contra esses seres e a sua proliferação pelas terras brasileiras, sobre o que já adiantamos a possível relação sugerida na obra entre os mortos-vivos e os colonizadores portugueses.

\section{Primeiro diálogo intertextual/intermidiático: os romances históricos}

A obra Independência ou mortos (2012) é, como mencionado, um romance gráfico, construído por meio da linguagem das histórias em quadrinhos, em que as imagens se coadunam à escrita para compor as cenas e construir, pela ilusão de movimento, o efeito de realidade, o qual, entretanto, é desafiado a cada momento pela forma como a linguagem se manifesta concretamente por meio dos balões. As histórias em quadrinhos engendram em seu pacto de leitura essa necessidade de se perceber entre os quadros uma continuidade, cabendo ao leitor o preenchimento daquele espaço intermediário, experienciando e ativando o funcionamento da narrativa.

Diferentemente das histórias em quadrinhos tradicionais, o romance gráfico se apresenta como um gênero caracterizado por certa unidade, com um relativo fechamento de sua diegese (a história e o universo criado pela obra) e uma relativa 
particularização de seu estilo. Isso se percebe principalmente quando se tem em vista a relação que alguns romances gráficos podem ter com uma história em quadrinhos seriada da qual ele teria se originado, como é o caso da obra Piada mortal, de Alan Moore, que conta uma história das personagens Batman e Coringa. Esse romance gráfico tem seus acontecimentos em parte integrados à cronologia canônica da personagem e à produção seriada de episódios, mas também possui em si uma existência autônoma, enquanto um universo não totalmente compatível com o das aventuras com as quais os leitores teriam contato periodicamente.

Mesmo que se constitua pela integração de ao menos dois elementos midiáticos, a imagem e a escrita, podemos tomar as histórias em quadrinhos em seu todo como textos. Se por um lado isso poderia ser tomado como a ampliação do conceito de texto, devemos lembrar que as histórias em quadrinhos ainda envolveriam o processo de interlocução e produção de sentidos que se dá no jogo entre o autor/narrador/enunciador e seu(s) leitor(es)/interlocutor(es). Ao comentar sobre a importância da semiótica para os estudos intermidiáticos ou interartes, mesmo como disciplina auxiliar, Clüver aponta que a obra de arte não-verbal pode também ser encarada como um texto e por meio da noção de signo: "uma obra de arte é entendida como uma estrutura sígnica - geralmente complexa, o que faz com que tais objetos sejam denominados 'textos', independente do sistema sígnico a que pertençam" (CLÜVER, 2006, p. 13).

Ainda que a imagem não se traduza completamente por palavras, ela pode ser percebida como constituída de significante e significado, no sentido de que há uma um lado sensível e um lado do conteúdo, há uma forma que desliza sobre um determinado sentido, possui com ele uma unidade que, por outro lado, é instável e posta em tensão e movimento a cada nova vez em que um leitor experiencia o processo de interlocução e reconstrução desse texto/imagem, dotando-o de significação. $\mathrm{O}$ aspecto narrativo das histórias em quadrinhos, além disso, ressalta o seu caráter de discurso, em que podem ser percebidos tanto elementos de situacionalidade histórico-social, quanto posições ideológicas em disputa. Certamente, a materialidade de cada tipo de signo, conforme a constituição de cada mídia, é importante de ser considerada nas análises, pois as diferentes maneiras como elas performam histórias e mundos ficcionais, bem como as diferentes maneiras pelas quais os leitores/espectadores se prostram frente à ou dentro dessas obras, é um dos pontos principais que pode ser colocado no debate das relações intermidiáticas.

Clüver também aponta a imprecisão do termo "estudos interartes" para a área que se dedicaria às relações entre a literatura e textos de outras mídias ou outras artes, não apenas pelo fato de que textos considerados não-artísticos proporcionam, em análises comparativas, trabalhos bastante produtivos, mas porque o próprio conceito de arte já seria visto como maleável, fruto de convenções histórica e socialmente constituídas. Trata-se do reconhecimento de que as diferenciações entre o que seria arte ou não "se baseiam em construtos motivados ideologicamente, ao invés de qualidades ontologicamente essenciais” (CLÜVER, 2006, p. 16). Daí que, pos- 
sivelmente, a noção de estudos intermidiáticos, por mais que exija a flexibilização e ampliação do conceito de mídia, seja mais interessante para poder contemplar de modo mais amplo as relações intertextuais que se estabelecem entre diferentes mídias, tanto no sentido de suportes, meios, quanto no sentido de linguagens.

Os romances gráficos podem ser compreendidos por uma noção abrangente, como a de texto intermídia: "o texto intersemiótico ou intermídia recorre a dois ou mais sistemas de signos e/ou mídias de uma forma tal que os aspectos visuais e/ou musicais verbais, cinéticos e performativos dos seus signos se tornam inseparáveis e indissociáveis" (CLÜVER, 2006, p.20). No nosso caso, a análise não apenas se detém sobre um objeto intermidiático, como busca analisar aquilo que chamariam de diálogos intermidiáticos, ou seja, como essa obra estabelece uma relação intertextual com outras mídias, buscando entender o funcionamento dessa relação e sua pertinência para a construção de sentidos da obra. Esse diálogo intertextual e intermidiático seria o que Clüver, a partir de Helbig, chamaria de relações intermidiáticas (CLÜVER, 2006, p. 24), não se tratando de uma transposição ou tradução intermidiática, no sentido de que não ocorre necessariamente um diálogo entre obras específicas.

Em Independência ou mortos (2012), uma das relações mais patentes que temos é com a produção de romances históricos, ou a ficção histórica em sua modalidade romanesca. O próprio título da obra já evoca a relação com o discurso histórico, ao apresentar um momento específico e reconhecível da história brasileira, o grito às margens do Ipiranga pelo qual D. Pedro I teria proclamado a Independência do Brasil. Esse discurso fundador do "independência ou morte", que institui um momento de nascimento da nação e a partir do qual se constrói todo um imaginário, é parodiado no título do romance gráfico, estabelecendo uma relação com a imagem que ilustra a capa e a contracapa: as personagens históricas lutando contra os zumbis, cercadas por eles.

Pelo evidente mote de construir uma história alternativa do Brasil, gestada a partir de elementos de aventura, ação e terror, típicos do universo cinematográfico e da cultura pop, um ponto interessante a ser pensando na análise dessa obra é a sua atitude frente ao discurso oficial da história, as relações que ela estabelece com esses discursos, comumente encontrados em livros didáticos tradicionais, e que se articulam com a manifestação de determinados valores de união, patriotismo e um conceito fechado de nação. O diálogo com o mito do zumbi, ainda que em sua forma típica da cultura pop, sinaliza que estaríamos em frente a um processo de ruptura, pelo menos aparente, com imagens cristalizadas das personagens históricas. A imagem da capa, por sua vez, mostra-se ambígua: pelo jogo de luzes com o qual organiza a sua composição e apresenta a figura de D. Pedro, coloca-o como um monumento, uma estátua celebratória: uma luz se projeta por baixo e ilumina suas feições imponentes, a figura do líder e herói que com sua espada atravessa a cabeça de um morto-vivo, o elemento extraordinário que se contrapõe ao tradicional e provoca um ruído na imagem do herói. 
No começo do romance gráfico temos uma espécie de contextualização histórica, situando em que momento e local se passa a história que será narrada. Estamos na Europa, em 1807, em meio às Guerras napoleônicas; o quadrinho inicial mostra um homem com a mão sobre o estômago, por dentro de sua farda militar, posição que remete o leitor diretamente à figura de Napoleão Bonaparte, sem a necessidade do texto escrito. Napoleão está acima do mundo, olha para ele como quem olha para seus domínios, sua expressão facial denota malícia e soberba:

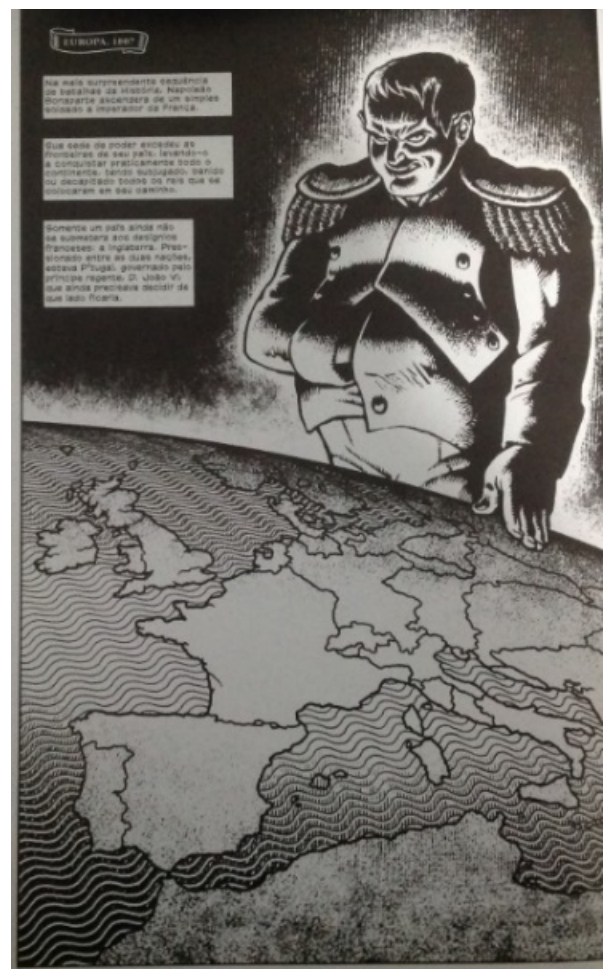

Figura 1 - FobIYA, 2012, p. 4.

O texto explica a situação de Portugal entre as duas grandes potências, França e Inglaterra. Os franceses exigiam que Portugal confiscasse bens e prendesse os ingleses em suas terras, fechando os portos para o império britânico, do qual era um grande aliado e parceiro comercial. A Inglaterra, para não perder essa aliança e domínio sobre os lusitanos, exigia a resistência deles frente aos franceses. A saída, no caso, foi transportar toda a corte para o Brasil, que deixaria de ser uma mera colônia. No romance gráfico a questão é colocada da seguinte maneira: "Entre as duas potências mais poderosas do mundo, entre a família e o povo, o sábio príncipe regente [D. João] teve de tomar a mais difícil das decisões..." (FoBIYA, 2012, p. 5); na página seguinte observamos o quadro abaixo, completando a frase da página anterior: "Fujam!", grita D. João, à frente da família real em fuga. Temos aqui outro recurso que marca essa obra, que é o uso do humor para construir uma determinada imagem das personagens históricas, dando a entender que o 
plano havia sido determinado de repente; ou, banalizando as dificuldades e ousadia do fato ao colocar as personagens sob a pecha de covardes. De fato, o fim do embarque da família real ocorreu logo antes da entrada das tropas napoleônicas em Lisboa, mas o quadro tenta reforçar o humor de uma situação que, por si própria, já seria bastante inusitada:

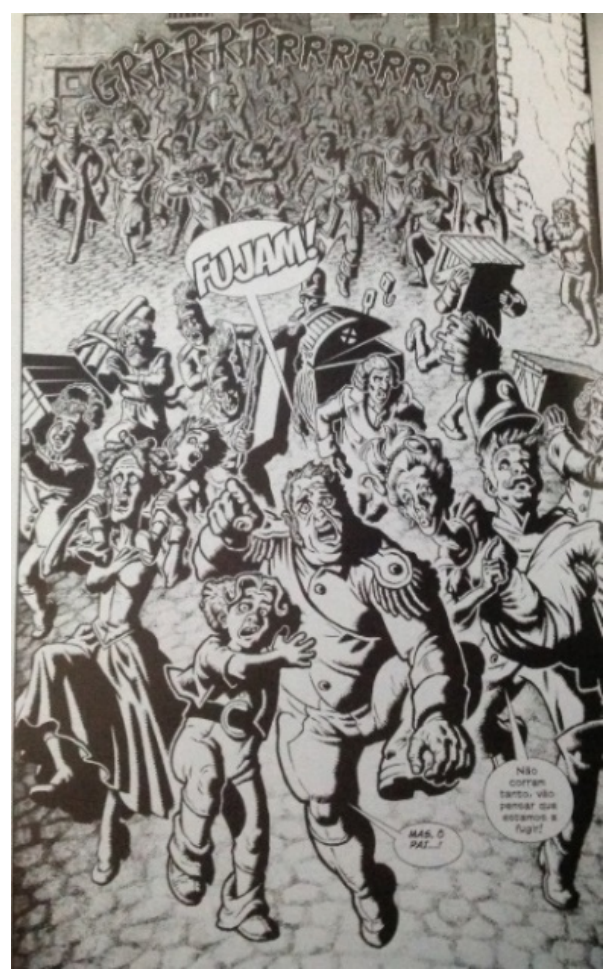

Figura 2 - FoBIYA, 2012, p. 6.

Na cena, temos a família real em destaque, da esquerda para a direita: a princesa Carlota Joaquina com o infante D. Miguel as suas costas, o infante D. Pedro agarrado ao pai, D. João, a rainha Dona Maria I sendo carregada por um soldado da guarda imperial. O corte entre o clima pesado do primeiro quadrinho, centrado em um vilanesco Napoleão, e a imagem carnavalizada da nobreza em fuga, afoitos e desesperados, busca criar o humor, mostrando a família real em uma situação inesperada e em uma postura nada heroica, rebaixados e fugindo do povo enfurecido. Na sequência, a rainha Dona Maria, com sua sanidade deteriorada, morde o soldado que a carregava e acaba ficando para trás. Surge, então, Francisco Gomes da Silva, o Chalaça, para protegê-la da ira dos populares; na verdade, o homem buscava ali um lugar no barco para fugir dos franceses, espaço que lhe é concedido pelo seu ato supostamente heroico.

O Chalaça é uma personagem conhecida por ter sido um dos amigos mais próximos de D. Pedro, seu secretário e alcoviteiro. O romance gráfico toma a liberdade de inseri-lo na trajetória da família real de maneira antecipada com relação 
à história oficial, um tipo de mudança que provavelmente teria mais uma motivação prática, trazendo já para a narrativa essa personagem, a fim de que ela cumpra seu papel misto de herói e malandro. Essas modificações vão sendo recorrentes ao longo da obra, seja pelo fato de que a releitura da história integrará a figura do zumbi, seja por critérios de seleção e organização do material histórico segundo o que é mais conveniente ao ritmo da história.

Dessa maneira, nessa primeira parte, assim como é sugerido em larga medida pelo título e pela capa da obra, é realizada a construção do pano de fundo histórico, situando em que ano estamos ancorando a obra em eventos e lugares conhecidos da história. Com isso, fica claro que estamos diante de uma ficção histórica, de um romance gráfico histórico. Nota-se, entretanto, um didatismo exagerado na forma como esse contexto histórico é apresentado: ele surge como fatos explicitados por uma voz narrativa (presente nos recordatórios, textos dentro de um quadrado que muitas vezes cumprem funções narrativas ou descritivas), como informações que a obra acredita serem importantes de se apresentar ao público; elas não estão integradas no contar propriamente dito, não surgem como decorrência do mostrar as personagens e do desenrolar do enredo. Essa explicitação é o tipo de recurso que não apenas enfraquece a narrativa, já que tanto parece um adendo didático, como parece menosprezar o conhecimento dos leitores sobre aqueles acontecimentos.

Segundo Lukács (1966), no romance histórico, o histórico não deveria surgir por uma descrição dos fatos ou por detalhes relacionados à aparência ou elementos individuais, tais como as características de personagens e do espaço, mas a partir dos movimentos e ações do povo, por meio da construção na narrativa da crise que poria forças antagônicas em disputa num determinado período histórico. Não devemos tomar a visão de Lukács sobre o romance histórico em sua versão mais tradicional, com grande teor normativo, como regra para avaliar obras, sobretudo as contemporâneas; contudo, essa visão é interessante para refletirmos acerca do que constituiria narrativamente e ficcionalmente o histórico e como ele não surge na obra pelas aparências, pelo que está na superfície, mas pela dinâmica específica da relação entre as personagens, pelo desenvolvimento dessas personagens ao longo dos eventos propriamente narrados pela obra. A explicitação de informações sobre a história se torna, portanto, irrelevante do ponto de vista da narrativa, além de pressupor o determinismo em torno do fato histórico, travando o dinamismo possível na forma como o leitor vai se colocar frente a essa obra, podando as ambiguidades possíveis inerentes ao discurso literário.

Durante a viagem, a narrativa de Independência ou mortos começa a dar espaço mais propriamente ao sobrenatural (algo já sugerido por um mendigo grunhindo como um monstro nas cenas iniciais e pela morte do soldado que carregava a rainha Dona Maria, após ser mordido por ela). Em resumo, ocorre uma infestação de mortos-vivos na nau Príncipe Real, que levava a família real, contaminação que se inicia com a Rainha: após falecer durante a viagem, ela começa a atacar e devorar aqueles que encontrava; esses, por sua vez, também se tornavam zumbis 
canibais e iam espalhando essa condição para os outros passageiros e tripulantes. Após lutarem contra as bestas, a família real, auxiliada por Chalaça e pelo Capitão do navio, consegue fugir; D. João, contudo, num misto de horror e alegria ao ver sua mãe voltando dos mortos, decide levá-la com eles no bote salva-vidas, junto a pedaços de carne para alimentá-la.

A nau, então, é destruída pelos ingleses que a escoltavam, por desconfiarem que os portugueses haviam traído a Inglaterra e se aliado à França. Por fim, os sobreviventes, mais a Rainha morta-viva, são resgatados por um outro navio da frota lusitana, embarcação que passa, a partir dali, a ser chamado de Príncipe Real, apagando da história a existência daquela outra nave, tentando anular qualquer indício do que havia acontecido (para o que D. João concede inúmeros títulos de nobreza àquela tripulação). Aqui temos um recurso digno de nota no que se refere ao modo como uma obra ficcional pode jogar com os signos da história, uma vez que fica evidente como há uma distância entre o que aconteceu e a forma como é transposto ao relato, manipulação que é construída a partir dos interesses dos grupos que detém o poder político e, consequentemente, o poder sobre a palavra.

\section{A intermidialidade e a configuração discursiva de D. Pedro}

Na configuração discursiva de D. Pedro no romance gráfico em questão, a intermidialidade cumpre um papel relevante, seja pelo processo de transposição para a linguagem e mídia dos quadrinhos de uma personagem histórica que se apresenta para nós por meio de uma constelação de objetos textuais e pictóricos (constituída por documentos, textos historiográficos e pinturas, mas também outras produções ficcionais como filmes, séries, romances), seja pela maneira como ele retoma elementos do imaginário popular para enaltecer ou satirizar a personagem. É interessante destacar que a voz narrativa que inicia a obra se apresenta, logo após o embarque da família real, em sua fuga para o Brasil, como a voz de D. Pedro, narrando em off e comentando os acontecimentos, como alguém que conta a história em retrospecto: "Meu nome é Pedro de Alcântara [...] Bragança e Bourbon... e esta é minha história" (FoBIYA, 2012, p. 12). Essa narração permite pensar que a história contada se constrói a partir da perspectiva dessa personagem, configurando uma espécie de narrativa autodiegética nesses momentos de explicitação da voz da personagem como condutora do que é apresentado visualmente, formatando-se a partir de uma focalização interna, ou seja, filtrada pelo olhar da personagem D. Pedro.

Em termos de narrativas escritas, como contos e romances, a denominação audiegético caracteriza o tipo de narrador que conta a sua própria história, como Bento Santiago em Dom Casmurro, de Machado de Assis. No entanto, nas histórias em quadrinhos, assim como outras mídias que dependem do visual (como o cinema e a televisão), a forma como a voz narrativa se constrói vai além desse elemento verbal: ela é a própria produção dos desenhos, a organização dos quadros, a seleção do que aparecerá nas imagens e como aparecerá, como a câmera no cinema constitui o narrador (aliada à edição e ao trabalho com a fotografia): "Mas a câmara, através 
de seu movimento, exerce no cinema uma função nitidamente narrativa [...] Focaliza, comenta, recorta, aproxima, expõe, descreve. O close up, o travelling, o 'panoramizar' são recursos tipicamente narrativos" (RosenfelD, 2007, p. 31). Nesse sentido que uma voz autodiegética nas histórias em quadrinhos se daria de maneira distinta dos romances, ou seria menos frequente em sua forma tradicional.

Uma possibilidade seria o caso, de feição metaficcional mais explicita (e por isso, talvez menos comum), de termos uma personagem quadrinista que se poria a contar sua própria história por meio dos quadrinhos que se apresentam ao leitor (como uma personagem diretor de cinema, que se apresenta como protagonista e como condutor dos enunciados fílmicos). Outra, talvez mais comum, pela flexibilidade e relativa facilidade, seria o caso de um narrador que, dentro no universo diegético, seria também um narrador ou ficcionista, cujo ato narrativo se traduziria semioticamente na obra imagética, como ocorre, em certa medida, com a obra que analisamos.

Dessa forma, em Independência ou mortos a focalização em vários momentos busca se construir pela perspectiva de D. Pedro; esse ponto de vista, entretanto, é muitas vezes relativizado, superando os limites da visão dessa personagem, trazendo acontecimentos e situações que ele não teria presenciado.

Dentre esses, estaria o complô arquitetado e engendrado por sua mãe, a princesa Carlota Joaquina, junto ao médico e pesquisador da recém-inaugurada Faculdade de Medicina. A fundação dessa faculdade por D. João, na obra, ocorre para que o médico pudesse estudar a condição de Dona Maria, mantida aprisionada, a fim de encontrar uma cura para a Rainha. Carlota Joaquina, por sua vez, tornase amante do médico; ambos tentam viabilizar uma forma de utilizar a condição da Rainha para produzir soldados especiais, criando um exército de zumbis para poder tomar o poder de D. João. D. Pedro tem conhecimento disso apenas no desenrolar do romance, quando Dona Maria foge de sua cela e passa a infectar a população. Contrariando D. João, que motivado pela proliferação dos zumbis queria voltar para Portugal (mas também por conta da determinação já proclamada dos nobres portugueses para que o rei voltasse à Europa, porque as tropas napoleônicas já haviam sido derrotadas, conforme o que é apresentado na história oficial), D. Pedro decide por ficar no Brasil e defender o povo. Assim, a resistência contra os portugueses, que queriam fazer abortar o desenvolvimento do Brasil e fazê-lo voltar à condição de colônia submissa a Portugal, torna-se, após a proclamação da Independência, uma resistência contra os zumbis. Com a morte do capitão das tropas portuguesas, é selada a união dos exércitos sob a liderança de D. Pedro na luta contra os mortos-vivos; a obra se encerra com o que seria o início da derradeira batalha contra os zumbis.

A apresentação do Dia do Fico nos permite analisar algumas das facetas que a obra busca construir sobre D. Pedro. Enquanto a família real embarcava para fugir do Rio de Janeiro, uma vez que D. João já havia percebido que as bestas estavam se disseminando pela cidade, uma pequena garota chama D. Pedro e lhe implora: 
“D. Pedro... O POVO PRECISA DE TI! Não nos abandone!" (FobIYA, 2012, p. 87; grifos do autor). Tendo subido no barco, o príncipe começa a discutir com seu pai, afirmando que não podiam abandonar o povo, enquanto D. João retomava o seu mote "Quando a força desigual, antes fugir que ficar mal!". D. Pedro, decepcionado com a atitude de seu pai, confirma se o Chalaça e a princesa Leopoldina, sua esposa, iriam acompanhá-lo; os dois afirmam que seguiriam o príncipe onde quer que ele fosse. D. Pedro, então, declama esta outra frase historicamente conhecida: "Está, pois, decidido! No dia de hoje, abraço meu destino! Se é para o bem de todos... E felicidade geral da nação... estou pronto! Diga ao povo que fico!".

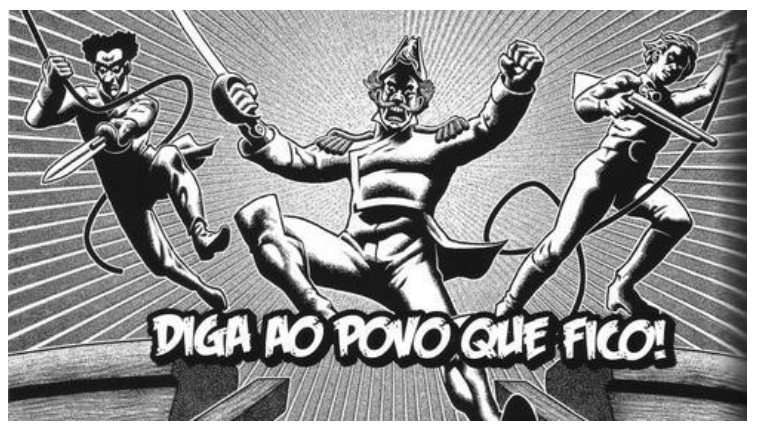

Figura 3 - Fobyia, 2012, p. 90.

Esse quadro, que fecha a página com a impactante frase em destaque, concentra a luz e direciona as linhas à figura centralizada de D. Pedro. Esse, por sua vez, é visto de baixo, o que engrandece a sua figura e o coloca na posição de salvador. Ele vem dos céus, dos altos de seu prestígio para salvar o povo, que se encontra indefeso na parte de baixo; os braços abertos a espada desembainhada e o punho fechado reforçam essa posição de luta a sua condição heroica. Como coloca Will Eisner (1989, p. 89) sobre a perspectiva nas histórias em quadrinhos, ela possui a função de manipular e/ou orientar o leitor para um determinado propósito narrativo, ou seja, ela conforma e dá pistas para a produção de sentidos e também para a produção de determinados estados emocionais no leitor. A composição da cena do Dia do Fico ressalta a faceta heroica da personagem histórica, sua honra cavalheiresca e altruísta, que se sobrepõe a uma possível desconstrução que a imagem dos zumbis poderia provocar na sua recriação ficcional.

\section{As referências intermidiáticas na composição de $\mathrm{D}$. Pedro}

A forma como o leitor irá perceber a figura de D. Pedro em muito se relaciona em Independência ou Mortos com as referências intermidiáticas que podem ser inferidas da maneira como ele é configurado na obra. A fim de tornar a análise de fenômenos da intermidialidade mais produtiva, Irina Rajewsky estabelece três subcategorias distintas para o estudo de fenômenos intermidiáticos: 1) a primeira delas seria a transposição midiática, em que uma obra traduz para outra mídia uma determinada obra de partida, o que chamariam comumente de adaptação 
intermidiática; 2) a intermidialidade pode também ser vista na categoria da combinação de mídias, como ocorreria em filmes, óperas e teatro, mídias distintas que se conjugam na construção de uma obra específica (uma obra multimídia ou mixmidia, conforme Clüver); 3) as referências intermidiáticas, que podem se constituir como uma alusão ou referência a uma obra de outra mídia, a um subsistema midiático (como um gênero) ou a uma outra mídia (RAJEwsky, 2012a, p. 58). Conforme ressalta Rajewsky, na referência intermidiática, "esse produto de mídia tematiza, evoca ou imita elementos ou estruturas de outra mídia, que é convencionalmente percebida como distinta, através do uso de seus próprios meios específicos" (RAJEWSKY, 2012b, p. 25).

Dessa forma, partindo da noção de referência intermidiática, podemos analisar a imagem abaixo. Nela, o rosto de D. Pedro parece retomar as feições da versão da personagem histórica como é apresentada no filme Independência ou Morte (1972), dirigido por Carlos Coimbra, filme que segue o molde dos épicos da ditadura militar e é centrado no enaltecimento do herói nacional, interpretado aqui pelo ator Tarcísio Meira. Essa referência reforça o teor nacionalista implícito no texto, paródia que se conjuga, de maneira em certa medida humorística, com a constituição do corpo do herói como se fosse um super-herói das histórias em quadrinhos, o físico musculoso e a atitude destemida. Associado a isso, as feições e o cabelo ainda nos remetem à personagem Wolverine, tanto da série de quadrinhos X-Men quanto dos filmes.

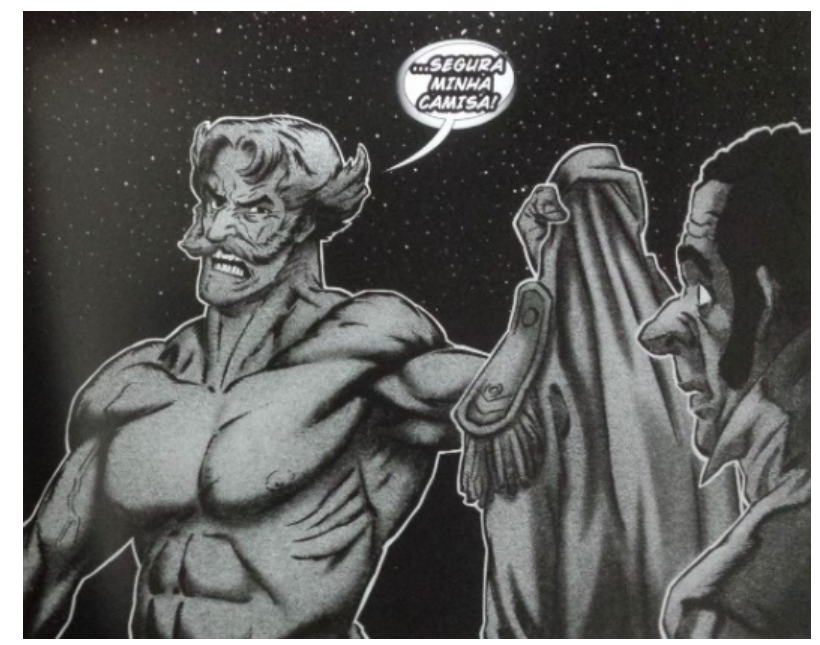

Figura 4 - Fobyia, 2012, p. 129.

Podemos dizer que a construção de D. Pedro nessa imagem tende a certa ambiguidade, já que, se por um lado ele está determinado ao ato heroico pelo seu povo, como se desenha na obra, sua construção imagética tende a criar um efeito cômico, como se estivesse ironizando a sua postura de macho man, que precisa tirar a camisa para exibir a performance de suas habilidades físicas. O ponto fundamental para a análise dessa obra, no sentido de sua releitura da história oficial, 
está se esse efeito cômico serve para desconstruir a personagem histórica, para efetuar uma paródia que rompa com as imagens cristalizadas dessas personagens, ou ela apenas busca fazer o leitor se divertir com o exagero e humor da imagem, sem que isso implique em repensar a representação de D. Pedro.

A imagem abaixo também retoma essa ambiguidade na forma como a personagem é construída, entre sua faceta heroica e exemplar e seu lado rebaixado:

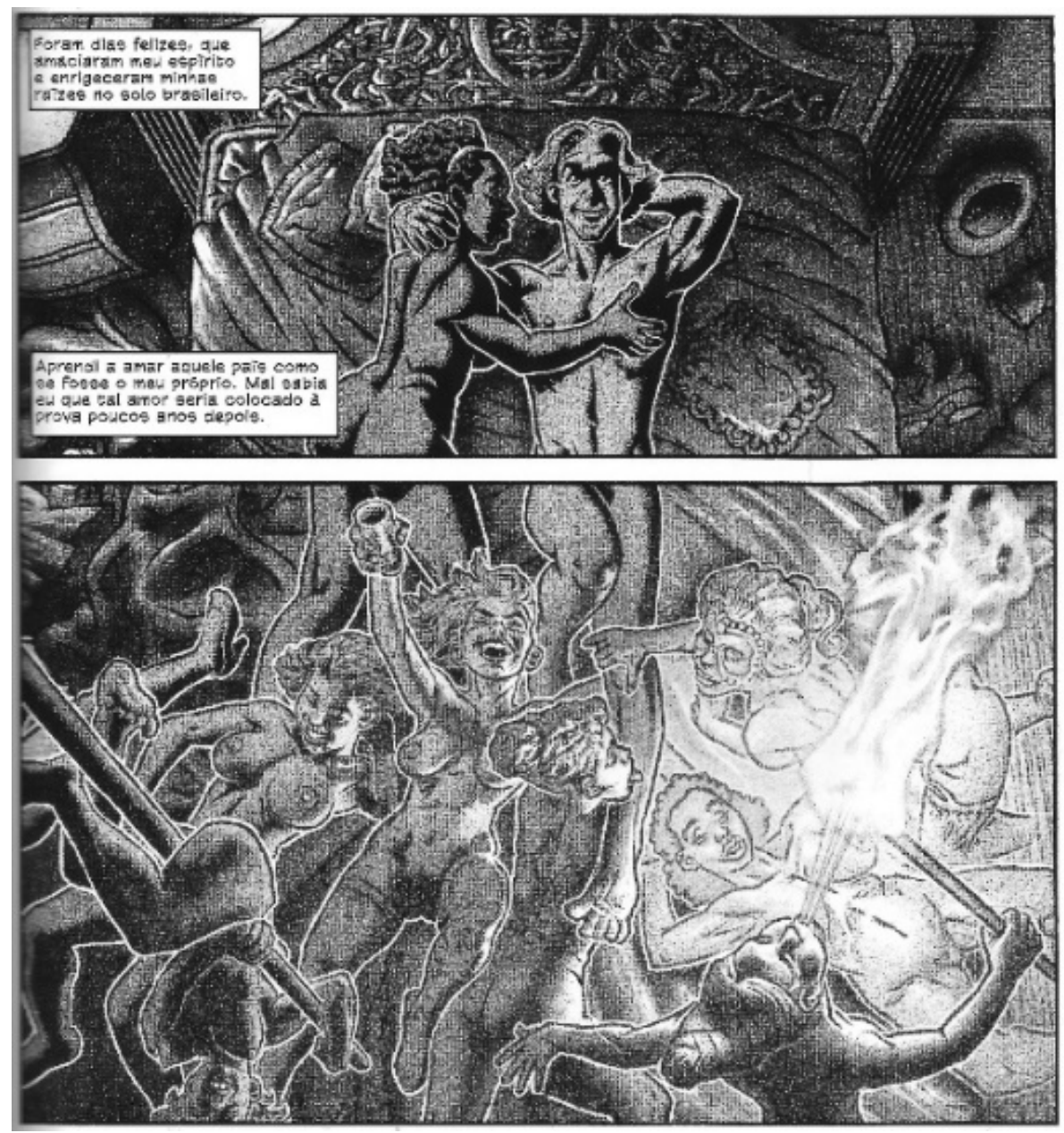

FigURA 5 - Fobyia, 2012, p. 63.

Temos aqui a personagem na cama com várias mulheres, relatando a forma como ele havia se enraizado nas terras brasileiras e percebia aquele lugar como um paraíso (no caso, evidentemente sexual). Pode-se entender que há até certo ponto uma tentativa de carnavalização e paródia do discurso oficial, colocando a personagem em uma situação rebaixada, processo que, no entanto, não é realizado de modo consequente, não produz uma crítica efetiva de um discurso hegemônico ou a ruptura de hierarquias. A personagem histórica D. Pedro foi, 
segundo o que consta em suas biografias e conforme é geralmente referido, um galanteador cuja trajetória está cheia de casos amorosos e relações extraconjugais. Se os livros sobre a história do Brasil por vezes já indicam essa característica, embora não se detenham tanto nela, fixou-se no imaginário popular esse perfil donjuanesco da personagem, sobretudo a partir da mídia televisiva (com série e novelas), mas também a partir de romances, como as obras de Paulo Setúbal, A marquesa de Santos (1925) e As maluquices do Imperador (1927), bem como O Chalaça (1994), de José Roberto Torero.

A relação de D. Pedro com as mulheres, conforme é apresentada nesses dois quadros, por outro lado, ressoa um conjunto de discursos falocêntricos e mesmo misóginos, colocando a figura do homem branco em uma posição de dominação sobre a mulher, da colônia e/ou escravizada, sem que haja sequer a indicação de questionamento dessas imagens cristalizadas num certo imaginário da historiografia e discursos das elites e do senso comum. Se ele é rebaixado na relação com uma aparência de determinada honra que se vende discursivamente, sua postura é enaltecida como a figura do garanhão, do macho alfa dominador, fazendo apagar o fato de que tal perfil também está intimamente ligado à figura do estuprador (não apenas da forma como entendemos esse crime sexual atualmente, mas também no entendimento de certa postura naturalizada do homem e do colonizador sobre as mulheres, sobre o domínio dos seus corpos). Desse modo, a obra acaba funcionando para legitimar preconceitos, ecoando vozes e posições bastante tradicionalistas, agindo da mesma maneira que os discursos oficiais, no projeto de criar uma suposta união da nação, apagando as vozes destoantes, dos excluídos da sociedade, da história e da palavra.

Essas questões acerca da configuração discursiva de D. Pedro estão relacionadas também com o processo de edição da história que o romance gráfico efetua. Uma das omissões mais significativas da obra é a da personagem Domitila de Castro, a Marquesa de Santos, tida como a mais importante e poderosa amante de D. Pedro. No posfácio do romance gráfico, os criadores justificam essas edições por motivos de economia narrativa, de falta de espaço para certos acontecimentos e personagens, bem como para reforçar o vínculo afetivo entre o príncipe e sua esposa, a princesa Leopoldina. A despeito do que teria sido a intenção dos autores (embora, nesse caso, ela corrobore os sentidos que a leitura da obra suscita), não se pode negar os efeitos de sentido que esse tipo de recorte acaba criando, mostrando-se principalmente como moralizantes na configuração da diegese e da personagem.

Por mais que Independência ou mortos apresente aos leitores a infidelidade do príncipe e a sua vida sexual intensa, na medida em que eles editam a história para ressaltar o seu vínculo amoroso com Leopoldina, como uma relação que superaria as demais questões, o romance tenta normalizar essa ideologia que defende que o homem deveria ter maior liberdade sexual, enquanto a mulher deveria ser fiel, submissa e condescendente. Da mesma forma, é apagado todo o sofrimento pelo qual a princesa Leopoldina passara por conta da infidelidade descarada de 
D. Pedro, sugerindo esse ideal romântico e machista de que, contanto que haja um suposto amor no casamento, o homem teria o direito a ter as suas amantes. Além do mais, a Leopoldina desse romance gráfico, por mais que participe das batalhas como se fosse um ser ativo e destoante de uma figura tradicional da princesa, tem toda a sua ação e existência girando em torno do seu marido, ausentando-se os interesses próprios dela. Semelhante a essa exclusão da figura feminina e sua submissão, ocorre também a exclusão do povo, visto como frágil e ávido por alguém que os salve, bem como dos negros em condição de escravos, apenas surgindo na obra como instrumentos de força para a luta física.

\section{Considerações finais}

Conforme pudemos analisar, o romance Independência ou mortos, ao reler a história do Brasil e a personagem histórica D. Pedro, estabelece um processo de união de elementos de distintos níveis culturais, seja a figura do zumbi, advindo na forma como é utilizada aqui do universo do que muitos chamariam de cultura de massa, e o discurso historiográfico, que se envolve de uma erudição típica da alta cultura. Aproximando-os e colocando no mesmo plano, a obra permite uma espécie de zona intermediária de níveis culturais, problematizando a forma como esses níveis são encarados ou avaliados segundo critérios valorativos e hierarquizantes. A paródia do discurso oficial constrói um passado alternativo da história brasileira, lançando mão da figura do zumbi nesse processo de retirar as personagens históricas de um posto heroico e de uma imagem definitiva. Por outro lado, como verificamos em nossa análise, a problematização do discurso histórico e da forma como os acontecimentos são comumente conhecidos por nós ocorre apenas de maneira superficial; os zumbis e o humor parecem surgir muito mais para construir uma atmosfera de diversão, típica de um produto que tem por objetivo o mero entretenimento.

Em si, isso não é necessariamente um defeito, entretanto, torna-se problemático se considerarmos que esse romance gráfico, por mais que em sua aparência tenhamos uma subversão dos acontecimentos e personagens históricas, parece ser bastante tradicional na maneira como relê a história. Com isso, temos um D. Pedro que ainda está na posição de herói defensor do povo e dos oprimidos. É certo que essa imagem é parodiada e exagerada, tornando-se objeto de humor pelas relações que se estabelecem com os super-heróis das histórias em quadrinhos, pelo corpo musculoso e destrezas físicas quase sobre-humanas. No entanto, essas questões parecem servir mais para criar uma empatia com leitores acostumados com essas narrativas de aventura do que exatamente para carnavalizar a posição de D. Pedro, retirando-a de seu pedestal. Ao não acenar com nenhuma crítica, ironia ou posicionamento sobre a forma como é retratada a relação da personagem com as mulheres, a obra acaba de certo modo avalizando e ecoando esses posicionamentos, uma falta de conscientização ou reflexão sobre a reali- 
dade social que se apresenta também na maneira como, por exemplo, os negros surgem nesse recorte da história do Brasil.

Para além desses pontos, podemos perceber em Independência ou mortos uma constituição palimpsêstica, evidenciada pela maneira como a obra dialoga intermidiaticamente com a ficção histórica na modalidade romanesca, pondo em tensão o discurso histórico e a narrativa ficcional. Ao tomar a história como um dos campos possíveis de diálogo intertextual e encenar uma versão da personagem D. Pedro, essa obra integra uma constelação de textos que retomam esse personagem, que dialogam entre si por meio dessa referência compartilhada e por estabelecerem uma experiência de constituição de um imaginário.

\section{Referências}

Clüver, Claus. Inter textos/ Inter artes/ Inter media. Aletria. Belo Horizonte, p. 939, jul. dez. 2006.Disponível em: http://www.periodicos.letras.ufmg.br/index.php/ aletria/article/view/1357. Acesso em: 30 abr. 2019.

EISNER, Will. Quadrinhos e arte sequencial. trad. Luís Carlos Borges. São Paulo: Martins Fontes, 1989.

Esteves, Antonio Roberto. O romance histórico brasileiro contemporâneo. (19752000). São Paulo: Ed. Unesp, 2010.

FoBIYA, Abu. Independência ou mortos. Ilustração de Harald Stricker. Curitiba: Nerdbooks, 2012.

Hutcheon, Linda. Poética do pós-modernismo: história, teoria, ficção. tradução R. Cruz; Rio de Janeiro: Imago, 1991.

InDEPENDÊNCIA ou Morte. Direção: Carlos Coimbra. Interpretes: Tarcísio Meira, Glória Menezes. Produtora: Cinedistri. Brasil, 1972.

LuKÁcs, Georg. La novela histórica. tradução Jasmin Reuter. México: Ediciones Era, 1966.

Rajewsky, Irina. A fronteira em discussão: o status problemático das fronteiras midiáticas no debate contemporâneo sobre intermidialidade. In: DinIz, Thaïs Flores Nogueira. VieIra, André Soares (org.). Intermidialidade e Estudos inteartes: desafios da arte contemporânea. Belo Horizonte, Rona Editora: Fale/UFMG, vol.2, p. 51-74, 2012a. Disponível em: http://www.letras.ufmg.br/ site/e-livros/Intermidialidade\%2oe\%2oEstudos\%2oInterartes\%20-\%2oDesafios\% 2oda\%20Arte\%2oContempor\% $3 \%$ A2nea\%2O2.pdf. Acesso em: 30 abr. 2019.

RAJEWSKy, Irina. Intermidialidade, intertextualidade e "remediação": uma perspectiva literária sobre a intermidialidade. In. DINIZ, T. F. N. (Org.). Intermidialidades e estudos interartes. Belo Horizonte: UFMG, 2012. 
Rosenfeld, Anatol. Literatura e personagem. In: CÂNDIDo, Antônio (et al). A personagem de ficção. 11. ed. São Paulo: Perspectiva, 2007.

SetúbAl, Paulo. As maluquices do Imperador. São Paulo: Geração Editorial, 2008.

Setúbal, Paulo. A marquesa de Santos. São Paulo: Geração Editorial, 2009.

Torero, José Roberto. Galantes memórias e admiráveis aventuras do virtuoso Conselheiro Gomes, o Chalaça. São Paulo: Companhia das Letras, 1994.

Recebido em 30 de abril de 2019.

Aprovado em 20 de outubro de 2019.

\section{Resumo/Abstract/Resumen}

Intermidialidade e (re)construção histórica no romance gráfico Independência ou mortos

\section{Stanis David Lacowicz}

Partindo do campo de estudos sobre intermidialidade e ficção histórica, este trabalho analisa a reconstrução ficcional da personagem histórica D. Pedro I, no romance gráfico Independência ou Mortos (2012), de Abu Fobiya (roteirista, pseudônimo de Fabio Abu) e Harald Stricker (ilustrador e co-roteirista). Numa mescla de linguagem verbal e visual, essa obra narra desde a vinda da família real portuguesa ao Brasil (1808) até a proclamação e luta pela independência (1822). Entretanto, a fim de construir um passado alternativo, eventos históricos conhecidos são intercalados com um elemento sobrenatural, os zumbis devoradores de carne humana. Pretendemos, além disso, evidenciar a forma como algumas das relações intertextuais e intermidiáticas que se operam na obra são fundamentais para a produção de sentidos em torno da reencenação da história. Tomamos por base os estudos de Claus Clüver (2006) e Irina Rajewsky (2012a, 2012b) para tratar sobre os conceitos de intermidialidade, bem como de relações e referências intermidiáticas.

Palavras-chave: D. Pedro I do Brasil, ficção histórica, romance gráfico, intermidialidade.

Intermediality and historical (re)construction in the graphic novel Independência ou mortos

\section{Stanis David Lacowicz}

Based on the studies on intermediality and on historical fiction, this article looks at the fictional reconstruction of the historical character D. Pedro I of Brazil in the graphic novel Independência ou Mortos (2012), by Abu Fobiya (scriptwriter, pseudonym of Fabio Abu) and Harald Stricker (illustrator and scriptwriter). Using a mix of verbal and visual language, this novel narrates the time from the coming 
of the Portuguese Royal Family to Brazil (1808) until the proclamation and fight for Brazilian Independence (1822). Nevertheless, in order to rebuild an alternative past, known historical events are intertwined with a supernatural element: zombies that eat human flesh. Furthermore, we intend to evidence how the intertextual and intermediatic relations that operates in the novel are crucial to the production of emotions based on the re-staging of History. This work is grounded on the studies of Claus Clüver (2006) and Irina Rajewsky (2012a, 2012b) in order to deal with the concepts of intermediality, as well as intermidiatic relations and references.

Keywords: D. Pedro I of Brazil, historical fiction, graphic novel, intermediality.

Intermedialidad y (re)construcción histórica en la novela gráfica Independência ou mortos

\section{Stanis David Lacowicz}

Basándonos en estudios sobre intermedialidad y ficción histórica, en éste trabajo pretendemos analizar la reconstrucción ficcional del personaje histórico D. Pedro I de Brasil en la novela gráfica Independência ou mortos (2012), de Abu Fobiya (guionista, seudónimo de Fabio Abu) y Harald Stricker (ilustrador y coguionista). En una mezcla de lenguaje verbal y visual, ésta novela narra el traslado de la Familia Real Portuguesa hacia Brasil (1808) hasta la proclamación y lucha por la Independencia de Brasil (1822). Sin embargo, para reconstruir un pasado alternativo, conocidos eventos históricos son intercalados con un elemento sobrenatural: los zombis devoradores de carne humana. Además, tenemos la intención de evidenciar cómo las relaciones intertextuales e intermediáticas que se perciben en la novela son fundamentales para la producción de sentidos alrededor de la reescenificación de la Historia. Este trabajo está fundamentado en los estudios de Claus Clüver (2006) e Irina Rajewsky (2012a, 2012b) para manejar los conceptos de intermedialidad, además de las relaciones y diálogos intermediáticos.

Palabras clave: D. Pedro I de Brasil, ficción histórica, novela gráfica, intermedialidad. 